\title{
Accessible Tourism: Determinants and Constraints; A Demand Side Perspective
}

\author{
Dr.Bindu.V.T* and M.kiruthika Devi* \\ *Assistant Professor, **Research scholar, Department of Tourism Management, Avinashilingam University for \\ women Bharathi park Road, Mettupalayam Road, Coimbatore-641 045, Tamilnadu-India
}

\begin{abstract}
Accessible tourism focuses mainly on inclusive tourism or tourism for all. Accessible tourism enforces mainly barrier free environment in all the 3A's of tourism. Constraints of many kinds inhibit people with disabilities and reduced mobility from enjoying the travel experiences. This article assorts the research work on accessible tourism in Tamil Nadu, India. Accessible Tourism is accessible for Person with Limited Mobility, but also for individuals with sensory disabilities, learning disabilities or chronic diseases.

Accessibility affects all areas of the tourism, basically the 3A's of tourism: access (transport), accommodation and attraction. The researchers have taken the loco motor differently abled people for the study to understand the determinants associated with $3 \mathrm{~A}$ 's of travel. The study proclaims the demand side perspective of accessible tourism comprising the loco motor disabled travellers of the region. It unveils the existing poor service available in the region inhibiting free movement of disabled community. The association of demographic factors with 3A determinants are also assessed. The main Constraints Environmental or Structural constraints, Interactive barriers or Interpersonal constraints, intrinsic barriers or Intrapersonal constraints, helplessness and intention to travel (Darcy. S and Buhalis (2011) are also determined. The study results reiterates the existing poor services available for differently abled travellers and the determiners of accessible tourism and the associated constraints which can be suggestive cues while implementing supply side services for accessible tourism in the region.
\end{abstract}

Keywords: Accessible tourism, 3A's, Determinants, Differently abled, Constraints, Demand side perspective.

\section{Introduction}

Accessible Tourism (AT) is part of inclusive tourism which is further an integral part of sustainable tourism. It is an approach aiming to provide and facilitate leisure and recreational facilities to all. The barriers and constraints need to be mediated to foster inclusive tourism for all. Accessible is not only that a location is physically accessible but in a more general meaning, that every one regardless of disability can make use of the product or service. The accessibility principle is often thought of as being a concern only of disabled people. It is a myth the implementation of most accessibility measures benefit all. 'Accessible environment is an essential requirement for around $10 \%$, a need for $30-40 \%$ comfortable for all and problematic for no one.' (Carlos Buj, 2010).Everyone will potentially benefit from accessibility at some point in life. Developing AT is not merely the right thing to do; there is a social demand for it. Moreover as Scott Rains (2008) rightly commented AT is not charity, it is yet another good business. Needless to say the transitions towards a fully accessible tourism require resources. But there is a benefit to it, not only in a more just inclusive society, but also in plain economic terms for tourism business and destinations. Depriving disabled people of their vacation may contribute to their marginalisation (R.Hall D 2006).If the society wants to ensure the same opportunities for its members; it should share the costs of accessibility among all, rather than among those who need it. Accessibility is a question of justice that as a society we should face and resolve.

\subsection{Main Dimensions of Accessibility}

It involves a set of practices meant to enable the tourists who suffer a limitation in their relational ability as tourists. Such tourists have certain special needs at different facets of travel and stay, necessitating provision of such need sets accordingly to facilitate their travel. It is meant to cover all those having varying degrees of accessibility constraints as regards to participation in leisure, recreation and tourism opportunities, viz. disability, and other medical conditions requiring special care, senior citizens and others in need of temporary assistance. Non-accessibility to tourism opportunities is not often the fundamental issue but creating the provisions judiciously in such a way to address the related constraints emerges as central challenge.

\subsection{Types of Barriers for Disabled People}

Existing literature tends to suggest that persons with disabilities face a number of barriers to participation (UNESCAP, 2003), due to which, they enjoy comparatively less access to leisure or tourism opportunities. Smith (1987), one of the pioneers in this subject identified three main types of barriers: Environmental including attitudinal architectural and ecological factors; interactive barriers relating to skill 
challenges incongruities and communication barriers; and intrinsic barriers associated with each person's physical psychological or cognitive functioning level.

\subsection{Accessible Tourism in India}

The size of accessible marketwise people with disabilities, their family members, dependants and other potential people with reduced mobility was roughly up to $18.11 \%$ of India's population in 2001 . In other words the market segment of people with reduced mobility is roughly 186.3 million, even one fourth of this is economically viable it contribute 46.58 million which indeed is vital. (S.Babu, 2010) Where as in 2015 the population is 12928 million where as the disabled population is 219 million.( IndianMOT:2015) .The major five states of India with maximum disabled population are Uttar Pradesh(34 million).,Bihar(19million) West Bengal (18million),TamilNadu(16 million) and Rajasthan(14 million). The present study is conducted in Tamilnadu, the loco motor disabled person of TamilNadu is considered for the present study.

\section{Review of Literature}

PwD (people with disability) "need to identify information on accessibility to scenic spots, toilets, hotel accommodation, and transportation, as well as availability of assistance and presence of travel partners" (Yau et al., 2004).

It is estimated that 13 per cent of all travellers had some form of disability and this figure was predicted to rise, particularly with the ageing of the baby boomers, advances made in medical science that had become more adept at saving lives and with greater access to travel by a range of people.” Darcy \& Daruwalla, (1999)

Accessible tourism has been defined as: a process of enabling people with disabilities and seniors to function independently and with equity and dignity through the delivery of universal tourism products, services and environments .Preiser \& Ostroff, (2001) also recommends that majority of people will benefit from these provisions including the ageing population, parents with prams, and employees as it incorporates good design for a range of occupational health and safety requirements. Tourism is one activity that many people with disabilities feel must be sacrificed as it requires an orchestrated cooperation of physical, mental, and social capabilities, which are often adversely affected or compromised by a disability. Nevertheless, it is widely accepted that desire to travel is the same for persons with or without a disability. Packer and Carter (2005) Valuing the disability tourism market conference held in Australia reinforced the legitimacy of accessible tourism as both a market and an area that required further research. According to Darcy \& Dickson (2009) "Accessible tourism enables people with access requirements, including mobility, vision, hearing and cognitive dimension of access, to function independently and with equity and dignity through the delivery of universally designed tourism products, services and environments".. Ambrose, (2012) says "Making tourism accessible for all is a rational response to a foreseeable demographic trend, and a massive economic opportunity for the tourism sector." However Darcy (2010) also proclaimed that AT is yet a neglected and underestimated area of sustainable tourism.

\subsection{Barriers of Disability}

According to Smith (1987), there are three main types of barriers and obstacles to participation: "environmental (including attitudinal, architectural, and ecological factors), interactive barriers (communication) and intrinsic barriers (relating to each person's own physical, psychological or cognitive functioning)."

Crawford et al. (1991) examined a "hierarchical" order of three constraints that influence leisure participation or non participation: intrapersonal constraints, followed by interpersonal constraints, and finally the structural constraints. Intrapersonal constraints refer to psychological conditions that are internal to the individual such as personality factors, attitudes, or more temporary psychological conditions such as depression or mood. Interpersonal constraints regard those constraints that arise out of interaction with others such as family members, friends, co-workers and neighbours. Structural constraints include such factors as the lack of opportunities or the cost of activities that result from external conditions in the environment. According to the model of Crawford et al., intrapersonal constraints that affect leisure preferences occur first. Right after intrapersonal constraints, interpersonal constraints take place, which influence interpersonal compatibility. Finally, participation or non-participation is dependent on structural constraints. The model elaborated by Crawford et al. was later tested, revised and modified by other researchers. Turco et al. (1998) identified constraints for $\mathrm{PwD}$ within four major tourism sectors and distinguished barriers concerning attractions (e.g., site inaccessibility), information (e.g., unreliable and inaccurate information sources about a destination and its accessibility), transport (e.g., difficulty in transferring between flights, inaccessibility of airplane restrooms), and accommodation (e.g., inaccessible rooms and bathrooms, restrictive appliances such as lamps and TVs, and front-desk counters that were too high). 
McKercher et al. (2003) identified a number of exogenous obstacles that may inhibit travel, limit options or reduce satisfaction. Such obstacles include: Architectural barriers, such as steps, inaccessible washrooms, inaccessible hotel accommodations, etc.; ecological barriers, such as uneven footpaths, tree roots and other exterior obstacles; transportation barriers, especially of the local transport variety including cars, buses and taxicabs; legal barriers, when rules or regulations prohibit people with disabilities from bringing needed equipment with them; communication difficulties, both in the individual's home and at destination; attitude barriers, due to negative attitudes from service providers; information barriers, due to inaccuracy of data about site accessibility.

Elimination of physical barriers is only one part of the issue. Unless appropriate enabling environments are facilitated and the individual is empowered to take advantage of these environments, people may still not have access to tourism. For a PwD, going on holiday is more than overcoming these physical barriers. Kwai-sang Yau, McKercher and Packer, (2004). Typically tourism participation of PwD runs up against a "plethora of barriers", among which: a lack of information on accessibility and accessible facilities; a difficulty in finding accommodation which is really and totally accessible (because "accessible" is not always accessible, especially when it comes to hotels); a difficulty in booking accessible accommodation even when it did exist; a lack of carers or additional costs for care givers; site inaccessibility and scant information about accessible sites; economic constraints. The last point stresses that, for some people with disabilities, holidays are not possible because of financial restrictions. Financial restrictions "are clearly associated with disabilities in that these restrict access to the world of work" (Shaw \& Coles, 2004).Enabling environments should not just ensure access to all; they must also empower people with access requirements to make informed decisions about whether accessible destination experiences are appropriate for their needs. Contrary to what many believe, research has shown that people with disabilities desire to travel, and many do it when their information and access needs are adequately addressed (Packer, McKercher and Yau, 2007).

\section{Need for the Study}

Accessible tourism is not widely popular in India this shows that there is huge need of accessible tourism facilities in all aspects of 3 A's- accommodation, attractions and access which help them to explore destinations. Darcy's review of demand side accommodation review explains there are various constraints which include lack of accessible accommodation that did not comply with access standard, problem of locating accessible accommodation inadequate level detail and accuracy information are some of the demand side constraints in the hotels (Darcy, 2010). From the literature it is clear that there is huge demand and prospects for AT in global level itself. In India AT is neither explored nor redressed. In 2010 Sudeshna Babu's problems and prospects of AT along with (MOT) ministry of tourism in India is one and may be the only study of its kind. By understanding the size of AT in India the need to redress is highly inevitable. In this background the researchers have taken a study to find out the determinants and constraints of AT from the perception of tourists, with special reference to Tamil Nadu. The study explores various constraints, demanded services at (3A's) attractions, and accessibility at hotel and transportation for differently abled people in TamilNadu. In TamilNadu accessible tourism has not yet been implemented. The researcher has taken the loco motor differently abled people for the study to understand the current facilities and to suggest effective cues for enabling AT in India.

\section{Objectives}

- Assess the current level of accessibility in (3 A's) of travel and hospitality.

- Study the various factors of demanded services.

- Understand different constraints of accessible tourism.

- $\quad$ Suggest effective measures for accessible tourism in Tamil Nadu.

\section{Analysis and Discussion}

For the purpose of the study, loco motor disabled people in TamilNadu were selected for the study. 200 disabled (loco motor) people all over TamilNadu who were willing and cooperative were approached for the study. The data were collected through a structured questionnaire. This assessed the socio demographic profile, level of accessibility, the demanded services and the various barriers or constraints of travellers

The first phase of study analyses the mean score in three different attributes. Firstly the level of accessibility is studied next is the demanded services available; lastly the five barriers or constraints faced by disabled people is studied. In the second phase with one way ANOVA the association of socio-demographic factors with level of accessibility, demanded services and constraints is identified.

(Fig.1) The perception of the loco motor disabled people on accessibility in TamilNadu ranges from 3.44 to 1.50 from which it is clear that majority of the respondents agree to the fact that TamilNadu is not 
having necessary accessible facilities for the tourists. It is inferred that accessible elevator posses the maximum mean value of 3.44 .

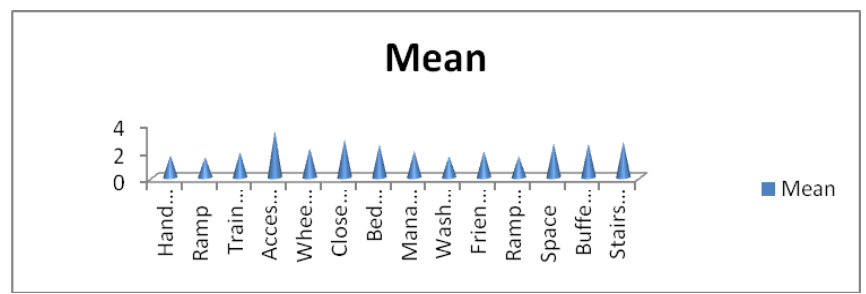

Figure.1 Accessibility

(Fig.2) The perception of the loco motor disabled people about Demanded services in Tamil Nadu ranges from 3.51 to 2.58 from which it is clear that majority of the respondents strongly agree to the fact that Tamil Nadu needs these services for the tourists. Electric scooter and Electric wheelchair are some of the most demanded service requested by the respondents.

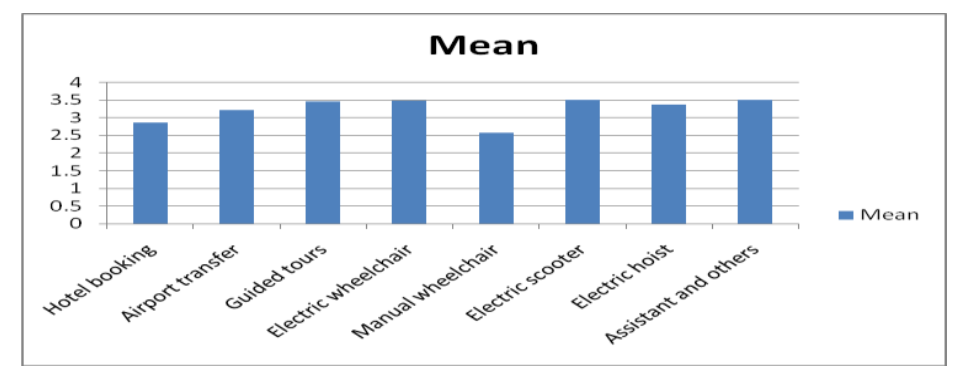

Figure.2 Demanded services

(Fig.3) The perception of the loco motor disabled people about Intrinsic Constraints in Tamil Nadu ranges from 3.31 to 2.22 from which it is clear that majority of the respondents agree to the fact that the tourists are facing a lot of intrinsic barriers.

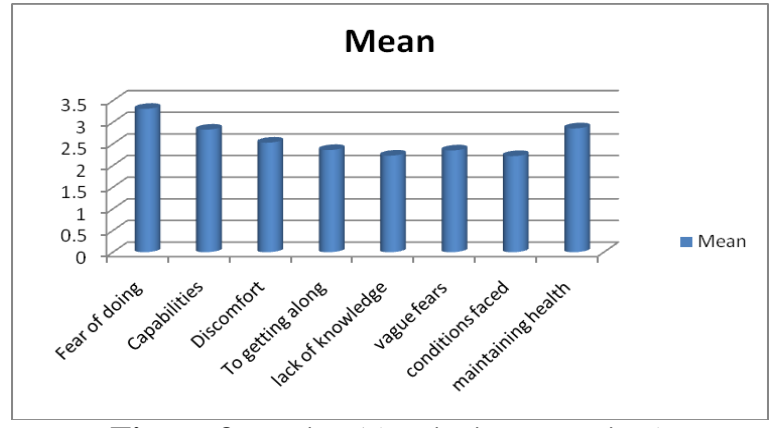

Figure.3 Barrier-1(Intrinsic constraints)

(Fig.4) The perception of the loco motor disabled people about Interactional Constraints in Tamil Nadu ranges from 3.21 to 2.64 from which it is clear that majority of the respondents agree to the fact that the tourists are facing a lot of barriers. On the whole Lack of experience has the highest mean value of 3.21 followed by Fear of being an object of others interest has the mean value of 3.16 .

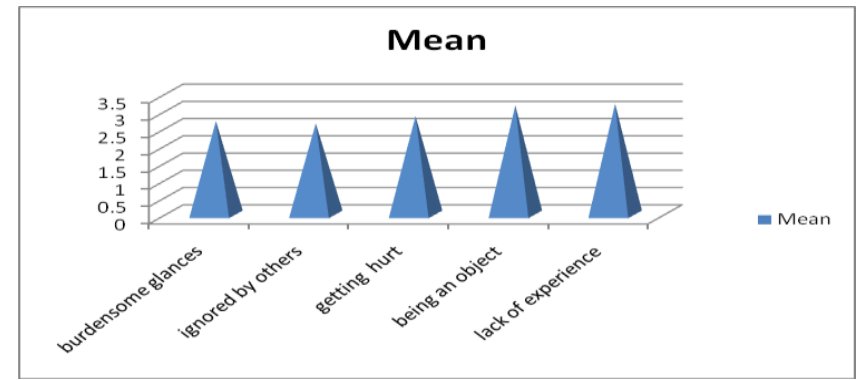

Figure.4 Barrier-2 (Interactional constraints) 
(Fig.5) The perception of the loco motor disabled people about Environmental Constraints in Tamil Nadu ranges from 3.24 to 3.12. The respondents agree to the fact that the tourists are facing a lot of barriers. On the whole Inconvenient facilities and accessibilities has the highest mean value of 3.24 followed by Specific environmental conditions (e.g. Cold or hot weather)

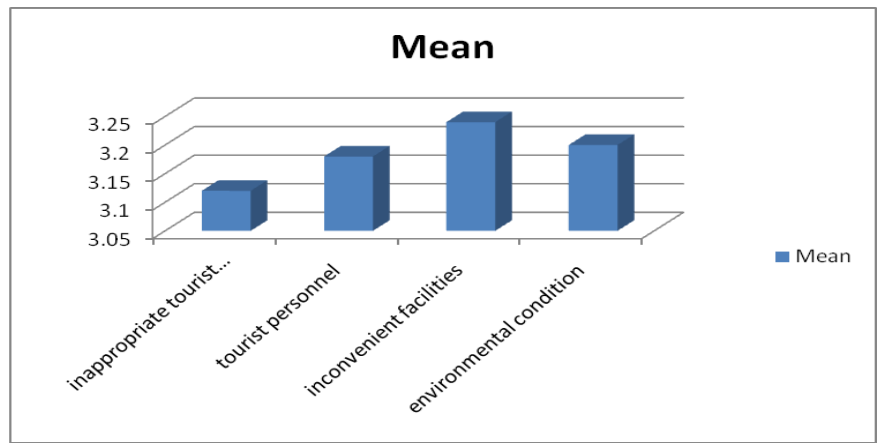

(Figure.5) Barries-3 (Environmental constraints)

(Fig.6) The perception of the loco motor disabled people about Helplessness in Tamil Nadu ranges from 3.07 to 1.93 from which it is clear that majority of the respondents agree to the fact that the tourists are facing a lot of barriers. Travel is not pleasurable has the highest mean value of 3.07 followed by Specific Comfortable travelling does not exist has the mean value of 2.38 .

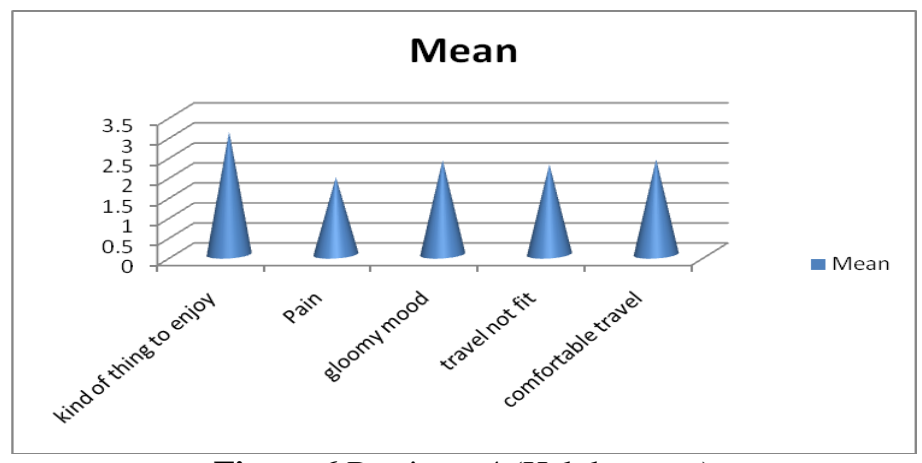

Figure.6 Barriers- 4 (Helplessness)

(Fig.7) The perception of the loco motor disabled people about Intention to Travel in Tamil Nadu ranges from 3.29 to 3.12 from which it is clear that majority of the respondents strongly agree to the fact that the tourists have the Intention to Travel.

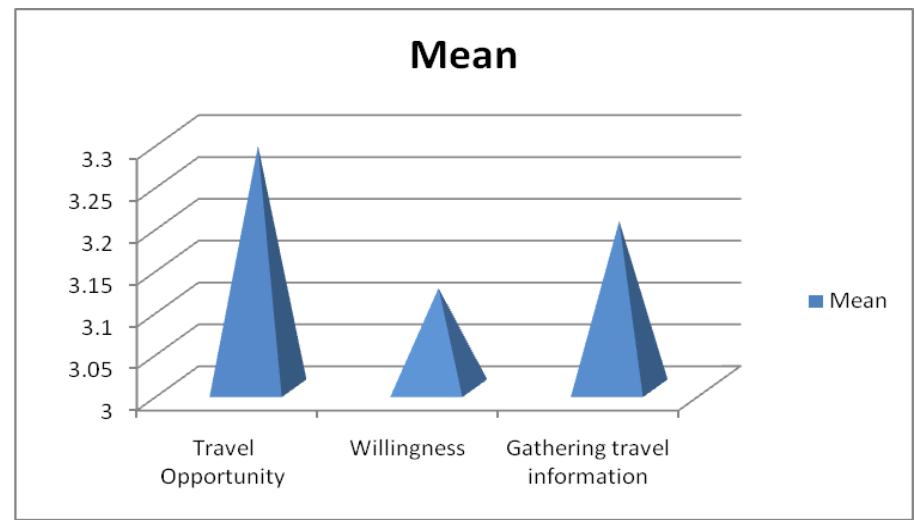

Figure.7 Barriers-5 (Intention to Travel)

Various socio demographic factors are associated with accessibility, demanded service and constraints. One way ANOVA is performed to find the relationship. The level of Accessibility shown relationship with age, education and occupation

The perception of accessibility level varies with age, education and occupation. Demanded service also has association with age, education and occupation. The constraints and barriers also show relationship 
with age, education and occupation. Darcy and Daruwalla (1999), and Cameron et al (2003) have studied that income has influence in Accessibility and barriers. The present study proves relationship with age, occupation and education.

\section{Findings}

In terms of accessibility the factor accessible elevator has a highest mean value of 3.44 , the perception of differently abled people about demanded services the factors like electric scooter and assistant and others has highest mean value of 3.51. In intrinsic constraints the factor fear of doing something by them self has a highest mean value of 3.31, in terms of interactional constraints the factor lack of experience has a highest mean value of 3.21,in environmental constraints the factors inconvenient facilities has a highest mean value of 3.24,in helplessness the factor tour is not kind of thing to enjoy has a highest mean value of 3.07, and in terms of intention to travel the factor travel opportunity has a highest mean value of 3.29. The present study reveals that very poor service is available in Tamil Nadu. The accessible travelers also face lots of constraints which need to be redressed at the earliest. Takeda and Card (2002) expressed the supply side perspective through an AABM Accessibility attitudinal barrier model. The model depicts accessibility and attitudinal barrier in 4 sectors of travel industry as encountered by the service providers. The model is broken into quadrant by axis. The horizontal axis indicates staff attitudes the vertical axis indicates accessibility. In their study also it showed most unfavourable condition.

Accessibility level prevailing in Tamil Nadu and the constraints mean value is depicted in the following graph. (Fig.8) it is shown that very poor accessible service is available. The accessibility is measured in all 3A's-access, attraction, accommodation. The mean value is ranging from 3.44 to 1.5. The constraints comprises of 25 factors which include Intrinsic constraints of 8 factors, interactional constraints of 5 factors, environmental constraints of 4 factors, 5 helplessness constraints and 3 intention to travel is considered for the present study.

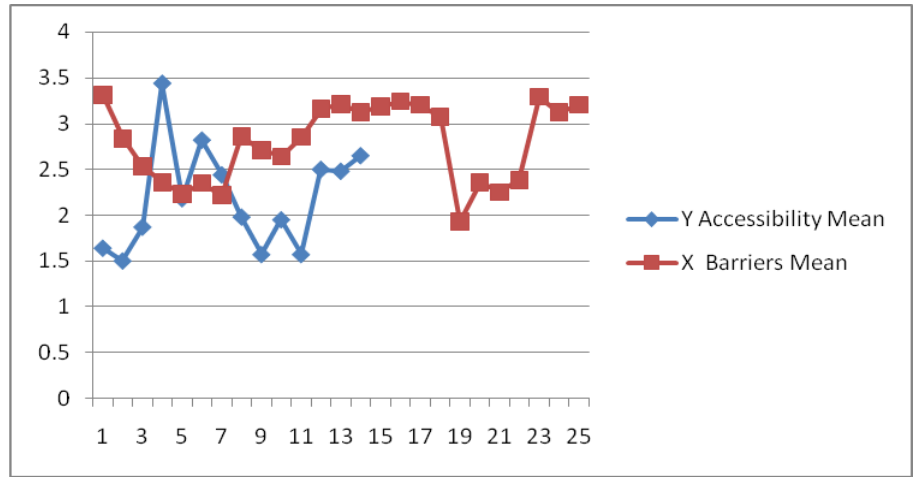

Figure.8 Accessibility with Barriers

(Fig.9) explains the level of accessibility with demanded service .ranging from a mean value of 3.51 to 2.87. Eight factors were considered for demanded service. The most demanded service were electric scooter and electric wheelchair.

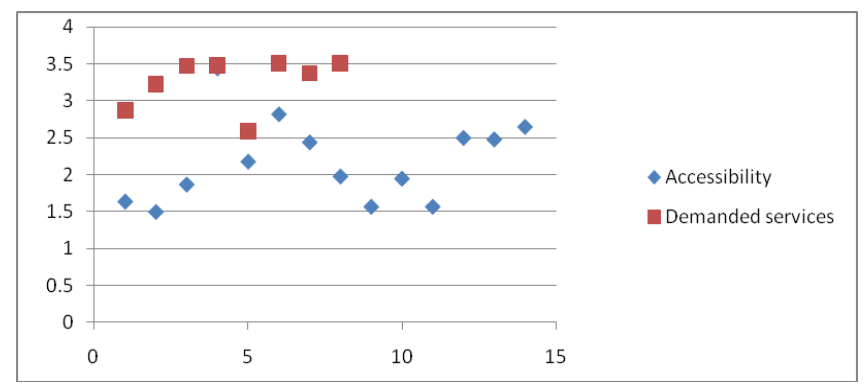

Figure.9 Accessibility with demanded services

It is concluded form the study that there is a relationship between accessibility with age. Occupation and education these socio democratic factors are major determinants of accessible tourism. These determinants have impact on barriers and demanded services. There is also a relationship between accessibility with education. There is a relationship between demanded services with age, education and occupation the factors like accessible hotel booking, accessible tour guided tours, electric wheelchair, manual wheelchair, 
electric scooter, assistant and others show significance value below 0.005 . There is difference among the group with different age on their opinion on the barriers. The factors show significance for barriers, viz intrinsic constraints, environmental constraints and intention to travel. There is difference among the group with different education on their opinion on barriers. There is also difference among the group with different occupation on their opinion on barriers. It shows significant between barriers and occupation, factors viz intrinsic constraints, and environmental constraints.

\section{Suggestion}

Raise awareness and provide specific training on accessibility issues for professionals and general public on limited mobility. Create an international ranking of accessibility with the best destinations in terms of accessibility to motivate service providers. Create destination guides with accessibility information and channels to provide the information in an accessible way. Government should form a partnership between, tourism industry accessibility experts, disabled persons' organizations and other civil society organizations for promotion, implementation, and monitoring of accessible tourism.

\section{Conclusion}

The study reveals that the existing facilities available in Tamil Nadu for AT is minimum. Only limited facilities are available in 3A's- access, accommodation and attraction. TamilNadu has not yet adopted the universal design approach. There must be barrier free system of transportation for the loco motor disabled people. Most of the disabled people have various constraints like intrinsic, interactional, environmental, helplessness and intention to travel. Demanded services like Electric wheelchair, Electric Scooter, Electric hoist is inevitable in AT. The facilities of disabled people should be made available in all cities of TamilNadu where these people can be benefitted.

From the study it is concluded that there is no awareness about accessible tourism in TamilNadu. Research findings suggest that environmental and attitudinal barriers pose major challenges to normal living of individuals with disabilities. The premise of accessible tourism is inclusive in nature. The identified determinants and constraints encapsulate the effective cues for successful implementation of AT in the state. It has been conceptualized to incorporate diversity of tourists with disability and reduced mobility to form an important tourist segment with specific travel requirements. The supply side determiners and constraints can be studied for future study. Similarly only loco motor disabled people have taken for the present study; the perception of other disabled people can also be studied in future.

\section{Bibliography}

[1] Australian Hotels Association. (1998). Catering for Guests with Disabilities: Survey of AHA Members. Canberra: AHA.

[2] Buhalis D., Darcy S. (2011), Accessible tourism. Concepts and Issues. Aspects of tourism, Channel View Publications, Bristolpp. 260-273.

[3] Buhalis D., Darcy S., Ambrose I. (2012), Best practice in accessible tourism. Inclusion, Disability, Ageing Population and Tourism, Channel View Publications, Bristol. Annals of Tourism Research, 31(4), 946-960.

[4] Buhalis, D. \& Darcy, S. (2010). Accessible Tourism Concepts and Issues: London: Channel View Publications.

[5] Burnett, J. J., \& Bender-Baker, H. (2001). Assessing the travel-related behaviors of the mobility-disabled consumer. Journal of Travel Research, 40(1), 4-11

[6] Cape Town.,(2002),The Cape Town Declaration for Responsible Tourism Available at http:WWW.icrtourism.org/capetown.html

[7] Carles Buj.,(2010)Paving the way to Accessible Tourism ,International Centre for Responsible Tourism heeds Metropolitan City

[8] Commonwealth Department of Industry Tourism and Resources. (2004). Tourism White Paper Implementation Plan: achieving Platinum Australia. Canberra: Dept. Of Industry, Tourism and Resources.

[9] Crawford, D. W., Jackson, E. L., \& Godbey, G. (1991). A hierarchical model of leisure constraints. Leisure Sciences, 13(4), $309 \mathrm{e} 320$.

[10] Darcy S., Pegg S., (2011), Towards Strategic Intent: Perceptions of disability service provision amongst hotel accommodation managers, International Journal of Hospitality Management, 30, pp. 468-476.

[11] Darcy, s. \& Daruwalla, p.s. (1999). The trouble with travel: people with disabilities and tourism. Social alternatives. 18 (1), pp.4146.

[12] Darcy, S. \& Dickson, T., (2009). A Whole-of-Life Approach to Tourism: The Case for Accessible Tourism Experiences. Journal of Hospitality and Tourism Management, 16(1), 32-34.

[13] Darcy, S. (1998). Anxiety to Access: The tourism patterns and experiences of New South Wales people with a physical disability. Sydney: Tourism New South Wales.

[14] Darcy, S. (2000). Tourism Industry Supply Side Perceptions of Providing Goods and Services for People with Disabilities. Sydney: report to New South Wales Ageing and Disability Department.

[15] Darcy, S. (2002a). Marginalized participation: Physical disability, high support needs and tourism. Journal of Hospitality and Tourism Management, 9(1), 61-72.

[16] Darcy, S. (2002b). People with disabilities and tourism in Australia: a human rights analysis. Paper presented at the Tourism and Well Being - 2nd Tourism Industry and Education Symposium, Jyvaskyla, Finland

[17] Darcy, S. (2004a). Disabling Journeys: the Social Relations of Tourism for People with Impairments in Australia - an analysis of government tourism authorities and accommodation sector practices and discourses. Unpublished Ph.D., University of Technology, Sydney.

[18] Darcy, S. (2006). Setting a Research Agenda for Accessible Tourism. Gold Coast: Cooperative Research Centre for Sustainable Tourism. 
[19] Darcy, S. et al., (2010) Inherent complexity: Disability, accessible tourism and accommodation information preferences. Tourism Management. 31, 816-826.

[20] Darcy, S., \& Taylor, T. (2009). Disability citizenship: an Australian human rights analysis of the cultural industries. Leisure Studies, 28(4), 419e441.

[21] Darcy, S., and Daruwalla, P.S. (1999), the Trouble with Travel: People with Disabilities and Tourism. Social Alternatives, 18(1), pp. 41-46.

[22] Darcy, S., Cameron \& Pegg, (2010). Accessible tourism and sustainability: a discussion and case study. Journal of Sustainable Tourism, 18(4), 515-537.

[23] Darcy, S., Pegg \& Packer, (2008). Developing business case studies for accessible tourism sustainable tourism online. Available at: http://www.sustainabletourismonline.com/86/growing-nichemarkets/developing-business-case-studies-for-accessible-tourism [Accessed on Feb 6, 2015]

[24] Daruwalla, P., \& Darcy, S. (2005). Personal and societal attitudes to disability. Annals of Tourism Research, 32(3), 549e570.

[25] Eichhorn, V., Miller, G., Michopoulou, E., \&Buhalis, D. (2008).Enabling access to tourism through tourism information schemes? Annals of Tourism Research, 35(1), pp. 189e210.

[26] Goldsmith, S. (1997). Designing for the disabled: the new paradigm. Boston: Architectural Press.

[27] Israeli, A. A. (2002). A preliminary investigation of the importance of site accessibility factors for disabled tourists. Journal of Travel Research, 41(1), 101e104.

[28] ITE (2003), Trip Generation Seventh Edition, Institute of Transportation Engineers (www.ite.org) (accessed on 2.03.2015)

[29] Iwarsson, S. \& Stahl, A., (2003). Accessibility, usability and universal design Emdash positioning and definition of concepts describing person environment relationships. Disability \& Rehabilitation, 25(2), 57, 61, 62.

[30] Jeremy Mattson (2012), Travel Behaviour and Mobility of Transportation-Disadvantaged Populations: Evidence from the National Household Travel Survey, Upper Great Plains Transportation Institute (www.ugpti.org), North Dakota State University; at www.ugpti.org/pubs/pdf/DP258.pdf.(accessed on 19.03.2015)

[31] Kwai-sang M., Bob McKercher \& Tanya L. Packer, (2004). Traveling with a disability: More than an Access Issue. Annals of Tourism Research, 31(4), 946-960.

[32] Market and Communication Research. (2002). People with Disabilities: a Market Research Report. Brisbane: Tourism Queensland - Special Interest Tourism Unit.

[33] McKercher, B., Packer, T., Yau, M. K., \& Lam, P. (2003). Travel agents as facilitators or inhibitors of travel: perceptions of people with disabilities. Tourism Management, 24(4), 465-474

[34] Olympic Co-ordination Authority. (1999). Access Guidelines (3rd ed.). Sydney: Olympic Co- ordination Authority.(Accessed on 22.02.2015)

[35] O'Neill, M., \& Ali Knight, J. (2000) Accessing the Disability Tourism Dollar - Implications for Hotel Enterprises in Western Australia. Paper presented at the Peak performance in tourism and hospitality research, Mt Buller, Victoria, Australia. (access on 2 5 February 2015).

[36] Packer, T. L., McKercher, B., \& Yau, M. K. (2007). Understanding the complex interplay between tourism, disability and environmental contexts. Disability and Rehabilitation, 29(4), 281e292.

[37] Packer, T., \& Carter, M. (2005). Out of the Blue! Valuing the disability market in tourism: Report of the 5th National Nican Conference, Perth,. Perth: Centre for Research into Disability and Society, Curtin University of Technology.(Access on20 Feb 2015)

[38] Packer, T., Small, J., \& Darcy, S. (2006). Grant Application - a scoping study to understand the tourism experiences of people with vision impairments (successful). Gold Coast: Sustainable Tourism Cooperative Research Council.

[39] Preiser, W. F. E., \& Ostroff, E. (2001). Universal Design Handbook. New York: McGraw-Hill.

[40] Rains, S. (2004). Universal Design and the International Travel \& Hospitality Industry. Paper presented at the Designing for the 21st Century III, Rio de Janeiro, Brazil: 7th - 12th Jan, 2015.

[41] R.Hall D.,F.B,(2006).Tourism and welfare : ethics, responsibility and sustained well being.CABI

[42] Ruys, H., \& Wei, S. (1998). Accommodation needs of mature Australian travellers. Australian Journal of Hospitality Management, 5(1), 51-59.

[43] Shaw, G., \& Coles, T. (2004). Disability, holiday making and the tourism industry in the UK: a preliminary survey. Tourism Management, 25(3), 397-403.

[44] Standards Australia. (1998). AS 1428.2-1992 design for access and mobility. General requirements for access-new buildings (3rd Ed.). Home bush: Author.

[45] Sutheeshna Babu.,Charusheela Yadav \& Saurab Dixit(2010)” Problems \& Prospects of Accessible Tourism in India ,Report in Ministry of Tourism

[46] Takeda, K \& Card J (2002).Tour Operators and Travel agencies: barriers encountered when providing package tour to people who have difficulties in walking. Journal of Travel \& tourism marketing,12(1),pp47-61

[47] Turco, D. M., Stumbo, N., \& Garncarz, J. (1998). Tourism Constraints - People with Disabilities. Parks and Recreation Journal, 33(9), 78-84.

[48] United Nations. (2006). Convention on the rights of persons with disabilities. New York: United Nations. Http://www.un.org/esa/socdev/enable/rights/convtexte. Htm United Nations General Assembly A/61/611 e 6 December 2006 (Accessed 20.01.2015).

[49] United Nations. (2006). Draft Convention on the Rights of Persons with Disabilities. Retrieved 10 October, 2006, from http://www.un.org/esa/socdev/enable/rights/ahc8adart.htm (accessed on 20.01.2015)

[50] Westcott J., 2004, improving information on accessible tourism for disabled people, European Commission, Luxembourg. Http:// ec.europa.eu; (accessedon 27.01.2015) pp.7.

[51] Yau, M. K.-s., McKercher, B., \& Packer, T. L. (2004). Buhalis D., Darcy S. (Eds) (2011), Accessible tourism. Concepts and Issues. Aspects of tourism, Channel View Publications, Bristol.

[52] Yuhua Bi, Jaclyn A. Card \& Shu.T Cole(2007),Accessibility and attitudinal barriers encounterd by Chinese,travelers with physical disabilities, International journal of Tourism Research.pp205-216

[53] www.unwto.org (accessed on 24.3.2015) 